\title{
Short Communication \\ The Enigma of Type 3c Diabetes in Chronic Pancreatitis
}

\author{
${ }^{*}$ Corresponding author \\ Mitnala Sasikala, PhD \\ Senior Scientist \\ Head of Research Labs \\ Asian Health Care Foundation \\ Asian Institute of Gastroenterology \\ Institute of Basic Science and \\ Translational Research \\ Hyderabad 500082, Telangana, India \\ Tel. 914023378888 \\ E-mail: aigres.mit@gmail.com
}

Volume 1 : Issue 2

Article Ref. \#: 1000POJ1106

\section{Article History}

Received: December 1 $1^{\text {st }}, 2015$

Accepted: January $5^{\text {th }}, 2016$

Published: January $6^{\text {th }}, 2016$

\section{Citation}

Sasikala M, Talukdar R, Subramanyam C, Nageshwar Reddy D. The enigma of type $3 \mathrm{c}$ diabetes in chronic pancreatitis. Pancreas Open J. 2016; 1(2): 19-21. doi: 10.17140/POJ-1-106

\section{Copyright}

(C)2016 Sasikala M. This is an open access article distributed under the Creative Commons Attribution 4.0 International License (CC BY 4.0), which permits unrestricted use, distribution, and reproduction in any medium, provided the original work is properly cited.

\author{
Mitnala Sasikala ${ }^{1 \star}$, Rupjyoti Talukdar ${ }^{1}$, Chivkula Subramanyam $^{1}$ and Nageshwar Reddy \\ $D^{2}$ \\ ${ }^{1}$ Institute of Basic Science and Translational Research, Asian Health Care Foundation, Soma- \\ jiguda, Hyderabad 500082, Telangana, India \\ ${ }^{2}$ Asian Institute of Gastroenterology, Hyderabad 500082, Telangana, India
}

Pancreatogenic or Type $3 \mathrm{c}$ diabetes $(\mathrm{T} 3 \mathrm{cDM})$ is relatively a new entry in the complex world of diabetes study. While the general population and physicians are well aware of type 1 and type 2 diabetes mellitus, as evidenced by numerous study groups and the reams of guidelines on diagnosis and treatment of type 1 and type 2 diabetes mellitus, relatively much less is known, considered and documented about diabetes mellitus that occurs secondary to pancreatic diseases. A casual search of Pubmed reveals less than 100 entries on type $3 \mathrm{c}$ diabetes. This may be because physicians earlier considered type $3 \mathrm{c}$ diabetes to be of rare occurrence and thus a condition rarely considered in everyday practice. Yet, recent data on type $3 \mathrm{c}$ diabetes (T3cDM) showed that it might be more common than generally thought. Studies also propose that this clinically important condition might be consistently under and misdiagnosed in routine clinical practice. ${ }^{1}$

The World Health Organization (WHO) and American Diabetes Association (ADA) have categorized diabetes occurring as a result of benign and malignant disease to exocrine pancreas, such as chronic pancreatitis, hemochromatosis, cystic fibrosis, fibrocalculous pancreatopathy, pancreatic trauma, pancreatic cancer and pancreatectomy as Pancreaticogenic diabetes (T3cDM). ${ }^{2,3}$ It is estimated that about $78.5 \%$ of $\mathrm{T} 3 \mathrm{cDM}$ patients are with chronic pancreatitis and $8 \%$ of T3cDM are suffering from pancreatic cancer. ${ }^{4}$ Globally about $10 \%$ of the total diabetic population has been diagnosed for Chronic Pancreatitis (CP), which is characterized by progressive fibrosis, irreversible exocrine and early onset endocrine dysfunction of pancreas. Recurrent and intractable abdominal pain is the dominant clinical hallmark that mandates aggressive treatment. An initial population-based study in Kerala (1996), confirmed later by questionnaire based studies in the Asia Pacific region, has recorded the prevalence of CP to be 114-200/100,000 populations in southern India, which is markedly higher than that in western industrialized nations $(10-15 / 100,000) .{ }^{5}$ Importantly, patients report initially with diabetes and then diagnosed for $\mathrm{CP}$ with the mean age of diagnosing $\mathrm{CP}$ being less than 30 years. However, it is noted that about $30 \%$ of patients with CP have diabetes and more than $50 \%$ of these individuals will develop diabetes before 40 years of age. In comparison to the western countries wherein it takes about 10 years for diabetes to manifest in diagnosed CP patients, it is within 2 years between onset of CP and diagnosis of diabetes in Indian patients, indicating the rapid loss of endocrine functions in these individuals.

Although pathogenesis of diabetes in chronic pancreatitis has long been recognized, only recently it is classified as a distinct entity and guidelines have been developed supporting a specified diagnostic and therapeutic algorithm. ${ }^{6} \mathrm{~T} 3 \mathrm{C} \mathrm{DM}$ is distinct from Type 1 and Type 2 $\mathrm{DM}$ as it arises due to chronic inflammation and has unique clinical and laboratory parameters and is associated with high incidence of pancreatic carcinoma. Despite vast knowledge on autoimmunity and insulin resistance as causative factors of type 1 and type 2 DM respectively, very few studies have addressed the development of diabetes in CP so far. Endocrine deficiency and clinical diabetes seen in chronic pancreatitis is complicated by the presence of additional co morbidities such as maldigestion and malnutrition. 
Recommendations towards Detection, evaluation and treatment of T3cDM in chronic pancreatitis have been evolved at the Pancreas fest 2012. However, much less is known about the cellular events that culminate in T3DM. We observed that $38 \%$ of CP patients develop diabetes within 1-2 years after the diagnosis of CP suggesting early onset diabetes in these patients (unpublished). While such an observation was made after the occurrence of overt hyperglycemia, decreased insulin secretion in patients with long standing CP were documented earlier. ${ }^{7}$ Tests for insulin secretion after maximal $\beta$-cell stimulation with combined oral administration of glucose, intravenous administration of glucagon, and tolbutamide have demonstrated decreased $\beta$-cell secretory capacity even in patients with normal oral glucose tolerance; with progression to diabetes, the $\beta$-cell secretory capacity becomes markedly reduced. ${ }^{8}$ In addition, decreased glucose stimulated insulin secretion by the islet cells isolated from surgical specimens of chronic pancreatitis patients was recently demonstrated even in non diabetic CP patients. ${ }^{9}$ These findings indicate $\beta$ cell dysfunction early in the course of $\mathrm{CP}$, warranting efforts to understand the mechanism(s) leading to loss of $\beta$ cell function in $\mathrm{CP}$, so that progression of the disease to clinical diabetes can be arrested. In pursuit of such a goal, we had earlier profiled pancreatic tissue cytokines since $\mathrm{CP}$ is a progressive inflammatory disease and since cytokines are known to influence islet functions. The obtained results demonstrated that IFN $\gamma$, of all the elevated cytokines, decreased glucose stimulated insulin secretory functions of islets in CP. ${ }^{10}$ Though, it is now believed that insulin resistance also contributes to clinical diabetes in $\mathrm{CP}$, tissue sensitivity to insulin is not overtly impaired in chronic pancreatitis regardless of glucose intolerance or overt diabetes. ${ }^{11}$ From the above considerations, it is now recommended that patients with CP should be evaluated for their glycemic status by periodic measurement of fasting glucose levels or by estimating Glycated haemoglobin (HbAlC) levels and undertake glucose tolerance test if an abnormality is detected in these parameters. ${ }^{12}$ In addition to screening $\mathrm{CP}$ patients for detecting hyperglycemia for therapeutic management, identification of $\beta$ cell dysfunction even before the patient becomes diabetic might help in developing modalities to prevent overt hyperglycemia and clinical diabetes. Therefore, we evaluated glucose tolerance levels in non diabetic chronic pancreatitis patients to assess the prevalence of prediabetic condition and observed that about $30 \%$ of non diabetic CP patients show extended glucose tolerance curves (Data unpublished).

Future research needs to focus on identifying factors responsible for complexity of the disease leading to initiation of $\beta$ cell dysfunction, glucose intolerance and prediabetic status. Since chronic pancreatitis is an inflammatory disease, due consideration should be given to unravel causative factors of inflammation such as cytokines, chemokines, receptors, immune/ inflammatory cells and variations in gut microbiome which may contribute to aberrant $\beta$ cell signaling pathways. In addition, genetic susceptibility of CP patients to develop T3cDM needs to be investigated. If the prediabetic status could be identified in $\mathrm{CP}$ patients, arresting $\beta$ cell dysfunction during disease progres- sion may prevent clinical manifestation of T3cDM. Vigorous investigations in this direction should yield important results that would help in managing and arresting progression of Type $3 \mathrm{cDM}$ in $\mathrm{CP}$.

\section{CONFLICTS OF INTEREST}

The authors declare that they have no conflicts of interest.

\section{REFERENCES}

1. Hardt PD, Brendel MD, Kloer HU, et al. Is pancreatic diabetes (type $3 \mathrm{c}$ diabetes) under diagnosed and misdiagnosed? Diabetes Care. 2008Is; 31(Suppl 2): S165-S169. doi: 10.2337/dc08-s244

2. Expert Committee on the Diagnosis and Classification of Diabetes Mellitus. Report of the expert committee on the diagnosis and classification of diabetes mellitus. Diabetes Care. 2003; 26: 55-520. doi: 10.2337/diacare.26.2007.S5

3. American Diabetes Association. Diagnosis and classification of diabetes mellitus. Diabetes Care. 2011; 34: 62-69. doi: $10.2337 / \mathrm{dc} 10-\mathrm{S} 062$

4. Ewald N, Kaufmann C, Raspe A, et al. Prevalence of diabetes mellitus secondary to pancreatic diseases (type 3c). Diabetes Metab Res Rev. 2012; 28: 338-342. doi: 10.1002/dmrr.2260

5. Braganza JM, Lee SH, Mc Cloy RF, et al. Chronic pancreatitis. Lancet. 2011; 377: 1184-1197.

6. Rickels MR, Bellin M, Toledo FGS, et al. Detection, evaluation and treatment of diabetes mellitus in chronic pancreatitis: recommendations from pancreas fest 2012. Pancreatology. 2013; 13: 336-342. doi: 10.1016/j.pan.2013.05.002

7. Schrader H, Menge BA, Schneider S, et al. Reduced pancreatic volume and beta-cell area in patients with chronic pancreatitis. Gastroenterology. 2009; 136: 513-522. doi: 10.1053/j. gastro.2008.10.083

8. Domschke S, Stock KP, Pichl J, et al. Beta-cell reserve capacity in chronic pancreatitis. Hepatogastroenterology. 1985; 32: 27-30.

9. Mitnala S, Pondugala PK, Guduru VR, et al. Reduced expression of $\mathrm{Pdx}-1$ is associated with decreased beta cell function in chronic pancreatitis. pancreas. 2010; 39(6): 856-862. doi: 10.1097/MPA.0b013e3181d6bc69

10. Kumar PP, Radhika G, Rao GV, et al. Interferon $\gamma$ and glycemic status in diabetes associated with chronic pancreatitis. Pancreatology. 2012; 12: 1265-1270. doi: 10.1016/j. pan.2011.12.005

11. Yasuda H, Harano Y, Ohgaku S, et al. Insulin sensitivity in 


\section{PANCREAS}

pancreatitis, liver-diseases, steroid treatment and hyperthyroid-

ism assessed by glucose, insulin and somatostatin infusion.

Horm Metab Res. 1984; 16: 3-6. doi: 10.1055/s-2007-1014681

12. Ewald N, Bretze RG. Diabetes mellitus secondary to pancreatic diseases (Type 3c): are we neglecting an important disease?

European Journal of Internal Medicine. 2013; 24: 203-206. doi:

10.1016/j.ejim.2012.12.017 